\title{
$\underline{\text { Re-Imagining the Future in Finance Capitalism }}$
}

\section{Special Issue Editor \\ Aris Komporozos-Athanasiou \\ (University College London)}

What is the role of the imagination in the constitution of finance capitalism? How do the fictions, myths, and (ir)rationalities of finance shape society's ability to imagine the future in the face of mounting uncertainty? Scholars of capitalism have always been intrigued by the role of the fictitious and the sacred in political economy. They have sought to make sense of the ways in which the speculative dynamics of capitalism propel societies towards unknown and uncertain futures, blurring the boundary between reality and fiction through ceaseless projections of imagined value. For Marx, this dynamic was driven by the socially destructive operation of fictitious capital and commodity fetishism. For Weber, the capitalist spirit was embodied in the Protestant pursuit of salvation through wealth accumulation. Implicit in both foundational approaches is a 'negative' view of the capitalist imagination, anchored in the human desire for endless accumulation. Such a view remains dominant in many critiques of capitalism's current financialised form, often associating imagination with further shifts from a material to an abstract economy, from real to fictional values, and from rational to irrational expectations. This special issue takes a different approach to the question of future-making under financialisation. Together, the articles comprising this volume draw a rich picture of finance's own imagination, one that precedes such ontological divisions between the 'passions' and 'interests' that animate late capitalist societies.

Well over a decade since the crisis Global Financial Crisis of 2008, today's financialised economies are still marred by stagnation and uncertainty. Against this backdrop, the increasingly speculative nature of economic forecasting, and the accelerated trading of promises of all sorts (from algorithmic and derivative markets to contemporary electoral politics) put the role of imagination centre-stage. Contrary to conventional wisdom, imagining the future is not necessarily equal to 'fantasising' or to 'irrational exuberance' or the 'animal spirits'. Rather, it points to something much more fundamental: the power of finance to produce new social and political morphologies under conditions of profound uncertainty. Imagination therefore is both socially-generative and politically contested - it is what makes financial representation, (e)valuation, and speculation possible in the first place (Haiven 2014, Beckert 2016, Beckert and Bronk 2018). If that is the case, then it matters what and how social, political, and economic agents are able to imagine, and what material resources they draw in their attempts to do so. The battlegrounds for power under financialisation see intensified struggles for imagination and the formation of new alliances and frontlines (Komporozos-Athanasiou and Fotaki 2015; 2020).

The articles of the special issue confront these issues by mapping out a novel field of investigation into different, unique types of imagination underpinning finance capitalism in the years since the global financial crisis. They draw on a wide range of empirical contexts (including mineral exploration, agricultural derivative markets, financial education programmes, the financialisaton of creative work, and the role of future-oriented legitimacy in neoliberal politics) and a diverse set of countries (including the US and the UK, as well as less frequently studied financialised economies such as those of Sweden and Israel). The contributions made by the articles foreground the role of imagination in the temporality of finance, paying particular attention to the important yet often-overlooked Knightian distinction between uncertainty and risk (Knight 1921). In doing so they bring into relief the complex interplay between, on the one hand, material resources, infrastructures, and work practices, and, on the other hand, the imagined expectations, forecasts, and future predictions 
of economic agents. On the whole, the special issue applies a diverse set of epistemological perspectives to the study of these issues, from philosophy, cultural studies, political science, and those typically invoked in economic sociology - fields of work that do not often talk to each other.

The first two articles of the volume examine the transformation of future-making practices in two age-old fields of capitalist economy during the last decade: mining and farming. Ollafson studies closely the process of mineral exploration in Sweden, through analysing applications for permit to the Mining Inspectorate between 2010 and 2016 and interviewing key informants about their experiences of the exploration process. His work shows how projections of mineral deposits' potential future profitability are produced, and how 'explorationists' use such projections to 'manage' the future's uncertainty. By combining perspectives from the sociology of the future and economic sociology, Ollafson offers us a nuanced perspective on how imagined futures and their specific qualities are created and legitimised in industrial mineral exploration. He does so through a vivid account of important day-to-day, material practices of future-making. From 3D modelling for estimating hidden deposits' size and qualities, to 'diamond codedrilling' for identifying copper quantities, we see how mineral explorationists routinely come together as a collective to assess risks. These collective imaginings of the future allow them to engage head-on with a diverse set of unpredictable uncertainties around infrastructure, labour, and legislation, and to create 'stable' and 'robust' images of future mineability.

This link between the material and 'the imagined' is further explored by Dutkiewicz, who contributes an alternative analysis of the relationship between derivatives with their underliers. His article centres on the entanglements and divergences between 'real' and 'abstract' values in financialised hog farming. Dutkiewicz traces historically the commodification of pigs alongside the evolution of derivative markets in pig futures, arguing that financialisation is not merely 'a logic', but a lived practice whose outcomes are both uneven and unexpected. By paying particular attention to the ruptures between the imaginaries of financial actors, he shows how the divergence between pricing in financial markets and on-farm realities allows some producers to reap record profits through a unique form of biological arbitrage: where an underlier (pigs) can be used to profit from fluctuations in the price of a derivative (lean hog futures). A core insight offered in his study is that while financial and physical markets are inextricably interdependent, they are not fully integrated. The practices and imaginaries of actors at different nodes in value chains divide along the line between 'financial' and 'physical' actors, between those who deal in securities and those who deal in tangible commodities - whose importance, the article argues, remains greater than recent debates on financialisation are willing to allow.

The second set of articles of the special issue dig deeper into the human and social impact of financialisation. If imagining the future is dependent upon available economic resources, then the latter's unequal distribution - and resulting power differentials profoundly affect the capacity of social actors to control (and profit from) everyday life's uncertainty. Shukaitis and Figiel's article focuses on such unequal lived experiences of uncertainty, which have become starkly manifest in contemporary labour markets. Their study explores the conflicted nature of labour precariousness instilled in modes of creative work today, as new affective attachments to work develop under financialisation. Shukaitis and Figiel contend that many cultural workers' expansive and all-embracing relationship to work represents a new 'psychological contract' of labour for our uncertain times. Through such intensified psychological investment in work, creative imaginings of the future become increasingly financialised - subjected to the continued demands of valorization and return on investment. More than merely becoming financialised subjects in the present, the damning consequence here is a new relationship governing their imagination of the future, itself 
culturally mediated through their relationship with work. Importantly, any possibilities for resistance to financialisaton should not overlook this inseparability of finance from culture in labour value. With Hito Steyerl (2009), the authors urge us to not jettison passionate attachments to creative work altogether, but rather, to 'work through' ambivalence and uncertainty as a source of potentiality that could intervene into finance's contradictions. In that sense, the important transformations in labour discussed in the article may herald a dystopian financialised future, but they also contain the possibility of a future where creativity could form the basis of new struggles, and new horizons for solidarity.

Yet such 'productive' and radical social engagements with uncertainty are often precluded by financial institutions, and the insidious ways in which they control imagined futures through 'responsibilisising' individual citizens. Zeev and Maman discuss these issues in their in-depth analysis of financial education programmes in Israel. Their article illuminates the institutional mechanisms prompting subjects to make everyday choices (e.g. of insurance or savings) and to engage with financial instruments, while imagining the financial sphere not as a site of fundamental uncertainty but as a site of risk management. Zeev and Maman show how financial education operates on a political level, through circulating a fantastical image of 'predictability' of futures that are in fact fundamentally unknowable. Revealingly, they argue that the constitution of this new financialised subject through such programmes is itself an imaginative process. Calculability myths are in that sense essential narratives for embedding 'individual responsabilisation' (the idea that individuals are fully responsible for the financial decisions that determine their current and future economic welfare and security) in financialised societies. Finance's own imagined futures substitute those of social agents. The financial imagination thus asserts and reaffirms the validity of the promise made by finance to the general public: that individuals' responsible engagement with financial products is the way to assure their future financial security - ultimately normalising and expanding the impact of financialisation.

The concluding article of the special issue centres on the broader political implications of promises that are made and broken in financialised forms of neoliberalism. Jens Beckert explores the process by which neoliberalism renews its legitimacy in the face of persisting crisis. He proposes a novel theoretical concept for the study of this process - what he calls 'promissory legitimacy'. This term refers to the support political authority can gain from the credibility of promises political leaders make regarding future states of the world, when justifying decisions and persuading others to follow them in their proposed course of action. Beckert's article cogently demonstrates how the promissory legitimacy of neoliberalism evolved through the 1970s, 1980s, and 1990s, escalating in the projection of an imagined (that is, an intended but yet unrealised) future, which served to offset societies' experiences of rising economic inequalities. By contrast, in the aftermath of the 2008 crisis, Beckert contends that we have been experiencing a loss of credibility of neoliberal imaginaries, and a contraction of neoliberalism's promissory legitimacy. The exhaustion of neoliberal promises has had profound social and political implications: most important of all, a growing discontinuity between culture and social structure that corresponds to what Durkheim defined as anomy. The article argues that populist promises (such as those made by Trump and other ethno-nationalist leaders) deal with the uncertainty of the future by retreating into the imaginaries of an idealised past. Anomy thus best describes our current moment, when social structures shaped by the principles of neoliberalism continue to persist, even as they are confronted with the exhaustion of those principles' promissory legitimacy.

Considered together, the articles in this special issue offer new important insights into the variegated consequences of financialisation, from labour precarity and ecological destruction, to debt and risk inequalities and political instability. Importantly, running through the discussed studies like a thread, is a view of imagination that undergirds the 
future-making practices of financialised economies, while also animating social actors' own responses to the protracted crisis resulting from the failure of neoliberal promises. If chaos is not merely a 'condition' of our current political and social world, but increasingly also a lucrative resource for speculation across economy, society, and politics, where might hope for alternatives to financialised futures come from? Responses to this question can no longer afford to ignore the sociological role of finance's imagination - its ability to not only cleave and individualise, but also point to possibilities for resistance for those who choose to fight capital on its own turf.

\section{References}

Beckert, J. (2016). Imagined futures. Harvard University Press.

Beckert, J., \& Bronk, R. (Eds.). (2018). Uncertain futures: Imaginaries, narratives, and calculation in the economy. Oxford University Press.

Knight, F. H. (1921). Risk, Uncertainty and Profit New York. NY: Harper \& Row.

Komporozos-Athanasiou, A. and Fotaki, M. (2015). A theory of imagination for organization studies using the work of Cornelius Castoriadis. Organization

Studies, 36(3), 321-342.

Komporozos-Athanasiou, A. and Fotaki, M. (2020). The Imaginary Constitution of Financial Crises, The Sociological Review (In Press).

Steyerl, H. (2009). The Institution of Critique. In Art and Contemporary Critical Practice: Reinventing Institutional Critique. London: MayFlyBooks, pp. 13-19 